\title{
Atmospheric BTEX and carbonyls during summer seasons of 2008-2010 in Beijing
}

\author{
Yujie Zhang ${ }^{\mathrm{a}, \mathrm{c}}$, Yujing Mu ${ }^{\mathrm{a}, *}$, Peng Liang ${ }^{\mathrm{a}}$, Zhu $\mathrm{Xu}^{\mathrm{a}}$, Junfeng Liu ${ }^{\mathrm{a}}$, Hongxin Zhang ${ }^{\mathrm{a}}$, Xiaoke Wang ${ }^{\mathrm{a}}$, \\ Jian Gao ${ }^{\mathrm{b}}$, Shulan Wang ${ }^{\mathrm{b}}$, Fahe Chai ${ }^{\mathrm{b}}$, Abdelwahid Mellouki ${ }^{\mathrm{c}}$ \\ ${ }^{a}$ Research Center for Eco-Environmental Sciences, Chinese Academy of Sciences, Beijing 100085, China \\ ${ }^{\mathrm{b}}$ Chinese Research Academy of Environmental Sciences, Beijing 100012, China \\ ${ }^{\mathrm{c}}$ Centre National de Recherche Scientifique, Institut de Combustion, Aérothermique, Réactivité et Environnement (CNRS-ICARE), 45071 Orléans cedex 02, France
}

\section{H I G H L I G H T S}

- The atmospheric carbonyls and BTEX during summer seasons of 2008-2010 were reported.

- The yearly variations and sources origination of carbonyls and BTEX were analyzed.

- The OFPs of the pollutants were estimated and compared.

- The OFP of CO accounted for the largest proportion as individual species.

\section{A R T I C L E I N F O}

\section{Article history:}

Received 2 November 2011

Received in revised form

16 April 2012

Accepted 9 June 2012

\section{Keywords:}

Carbonyls

BTEX

Beijing

Photochemical activity

Ozone formation potential

\begin{abstract}
A B S T R A C T
The atmospheric concentrations of carbonyls and BTEX (benzene, toluene, ethylbenzene, m,p-xylene and o-xylene) were measured simultaneously in summers of Beijing from year 2008 to 2010. The total concentrations of formaldehyde, acetaldehyde and acetone in the consecutive summers, which were $33.4 \mu \mathrm{g} \mathrm{m}^{-3}, 36.7 \mu \mathrm{g} \mathrm{m}^{-3}$ and $48.6 \mu \mathrm{g} \mathrm{m}^{-3}$, respectively, were much lower than those reported in the summers of $2005\left(58.4 \mu \mathrm{g} \mathrm{m}^{-3}\right)$ and $2006\left(77.4 \mu \mathrm{g} \mathrm{m}^{-3}\right)$. The concentrations of BTEX in the summers were $16 \mu \mathrm{g} \mathrm{m}^{-3}, 21.5 \mu \mathrm{g} \mathrm{m}^{-3}$ and $15.4 \mu \mathrm{g} \mathrm{m} \mathrm{m}^{-3}$, respectively. The maximal contributions of photochemical reactions to atmospheric formaldehyde and acetaldehyde in the summers were estimated to be around 47.6-60.3\%. The average ozone formation potentials (OFPs) for carbonyls and BTEX as well as carbon monoxide in summer of Beijing were calculated as $166.1 \mu \mathrm{g} \mathrm{m}^{-3}, 65.4 \mu \mathrm{g} \mathrm{m}^{-3}$ and $100.8 \mu \mathrm{g} \mathrm{m}^{-3}$, respectively.
\end{abstract}

(c) 2012 Elsevier Ltd. All rights reserved.

\section{Introduction}

Carbonyl compounds and BTEX (benzene, toluene, ethylbenzene, m,p-xylene and o-xylene) are two important classes of the major organic pollutants in the urban air, and automobile exhaust has been recognized to be their dominant primary source (Baez et al., 2001; Larry et al., 1996; Liu et al., 2009a; Dutta et al., 2009). In addition, photochemical reactions of volatile organic compounds (VOCs) also make great contribution to atmospheric carbonyls concentrations in the urban areas (Larry et al., 1996; Grosjean, 1982; Carlier et al., 1986; Aschmann et al., 2001).

Both carbonyl compounds and BTEX play important roles in atmospheric chemistry and urban air quality (Atkinson, 2007). They are both recognized as important photochemical precursors for tropospheric ozone and second organic aerosols (Barletta et al.,

\footnotetext{
* Corresponding author. Tel.: +86 10 62849125; fax: +86 1062849117

E-mail address: yjmu@rcees.ac.cn (Y. Mu).
}

2008). Besides, photolysis of the carbonyls is an important source for atmospheric hydroxyl radical $(\mathrm{OH})$ and peroxy radicals $\left(\mathrm{HO}_{2}\right.$, $\mathrm{RO}_{2}$ ) which are further involved in photochemical reactions (Atkinson and Arey, 2003). Carbonyls and BTEX in the urban air have also aroused great attention due to their toxicity, mutagens, and carcinogens (Grosjean et al., 2002), e.g. the life risk of chronic leukaemia is $4.4-7.6 \times 10^{-6}$ when atmospheric concentration of benzene is equal to $1 \mu \mathrm{g} \mathrm{m}^{-3}$ (Crump, 1994).

Considering the important roles of carbonyls and BTEX in atmospheric photochemistry and their negative impact on human health, their ambient levels in the urban and rural atmosphere have been widely investigated all over the world. In EU and USA, monitoring of these compounds has been legislated and their air quality standards established (EPA, 1999). In Beijing, atmospheric BTEX and carbonyls were measured only by few groups with a focus on their pollution levels and source identifications (Pang and $\mathrm{Mu}$, 2006; Song et al., 2007; Duan et al., 2008; Liu et al., 2009a, 2009b; Xu et al., 2010). Furthermore, ozone formation potentials (OFPs) of various VOCs have aroused great attention for 
environmental scientists and policy makers because ozone pollution in Beijing has become more and more serious in recent years. Nevertheless, there were only two investigations about OFPs based on individual measurement for limited number of VOCs in Beijing. Xie et al. (2008) classified the OFP of 51 VOCs based on their measurement in the megacity, but their estimation lacked of the data of carbonyls. The estimation of Duan et al. (2008) considered the atmospheric carbonyls but the data used was only based on very short-term measurements (only four days in August). Although the chemical activities of $\mathrm{CO}$ is much lower in comparison with various VOCs, its concentration in urban area is usually $2-3$ magnitude higher than those of individual VOCs, and its $\mathrm{OH}$ loss rate in the air of Beijing was comparable to most VOCs species (Liu et al., 2009b). Consequently, the OFP of CO in urban area should be also considered.

In this study, the atmospheric BTEX and carbonyls were simultaneously investigated for three consecutive years (2008-2010) during summer seasons in Beijing to reveal their pollution levels and yearly variation trend, to seek for the reason for the yearly variations, and to estimate their contribution to OFPs.

\section{Experimental section}

\subsection{Field measure site}

Air samples were collected on a rooftop (20 $\mathrm{m}$ above the ground level) in the Research Center for Eco-Environmental Sciences (RCEES) which lies in the north of Beijing city $\left(39.8^{\circ} \mathrm{N}, 116.5^{\circ} \mathrm{E}\right)$ between 4 th and 5 th ring roads. The detail information about the sampling site was described in our previous studies (Pang and $\mathrm{Mu}$, 2006; Liu et al., 2009a).

\subsection{Sampling and analysis}

Carbonyls and BTEX were simultaneously sampled during summer seasons (June-August) from July 2008 to August 2010 (7:00-19:00 Beijing Time each day), with carbonyl samples collected at $2 \mathrm{~h}$ intervals and BTEX at $1 \mathrm{~h}$ intervals. The sampling days were selected according to the local weather forecast with average wind speed less than $4 \mathrm{~m} \mathrm{~s}^{-1}$, and no raining. In addition, to reflect the contribution of photochemical reactions to atmospheric carbonyls, at least three sunny days in each month were selected for sampling. The total sampling days in 2008, 2009 and 2010 were 26,18 and 15 , respectively.

The sampling process and the analysis procedure of atmospheric carbonyls were mainly based on the EPA TO-11A method (EPA, 1999), and the details have been described in our previous publications (Pang and Mu, 2006, 2007). Briefly, ambient air was drawn through a 2, 4-dinitrophenylhydrazine (DNPH)-coated silica gel cartridge (Waters, United States) by a mini-pump (NMP 830 KNDC, Germany) at a flow rate of $800 \mathrm{~mL} \mathrm{~min}^{-1}$ for $2 \mathrm{~h}$, and the corresponding DNPH hydrazones of carbonyls were separated by a Thermo ODS Hypersil reverse phase column $(5 \mu \mathrm{m}$, $250 \times 4.6 \mathrm{~mm}$ ) and automatically analyzed by an photodiode array UV detector (at $360 \mathrm{~nm}$ ) in an Alliance 2695 HPLC system (Waters, USA). The detected limit $(\mathrm{S} / \mathrm{N}=3)$ by this method was in the range of $80-200 \mathrm{ng} \mathrm{m}^{-3}$ for various carbonyls of $96 \mathrm{~L}$ sampling volume.

As for BTEX, they were sampled by drawing air through an absorption tube ( $15 \mathrm{~cm}$ long, $4 \mathrm{~mm}$ ID) filled with Tenax-TA (80-100 mesh, $100 \mathrm{mg}$ ) at a flow rate of $350 \mathrm{ml} \mathrm{min}^{-1}$ for $1 \mathrm{~h}$, and analyzed by a gas chromatography equipped with a Photo Ionization Detector (GC-PID, GC4400, East \& West analytical instruments, INC.) after thermal desorption. The method detection limit (with a signal-noise ratio of 2) for the benzene, toluene, ethylbenzene, m,pxylene and o-xylene were 0.01, 0.02, 0.06, 0.07 and $0.07 \mu \mathrm{g} \mathrm{m}^{-3}$, respectively. One blank sample was analyzed for each day, and found that the concentrations of BTEX in the blank tube were less than 3\% of those in the ambient air samples. Distinct breakthrough for benzene was found when the absorption tube was kept under ambient air temperature, but greatly improved when the tube was kept in a bath of ice-salt bag. Therefore, all samples were collected under the bath of ice-salt bag, and the collection efficiencies for benzene, toluene, ethylbenzene, m,p-xylene and o-xylene were $81.5 \pm 5.6 \%, 93.6 \pm 2.2 \%, 95.8 \pm 0.8 \%, 96.5 \pm 2.4 \%$ and $91.5 \pm 4.6 \%$ (the result of 10 reduplicate experiments with two absorption tubes in series), respectively. The recovery ratios for benzene, toluene, ethylbenzene, m,p-xylene and o-xylene were $95.7 \pm 3.1 \%, 99.2 \pm 2.6 \%$, $98.6 \pm 2.4 \%, 98.1 \pm 2.4 \%$ and $96.2 \pm 2.2 \%$ (the result of 22 reduplicate experiments), respectively. The details about preparation of the absorption tube, sampling and analyzing procedures have been described in our previous publication (Liu et al., 2009a).

Meteorological conditions (temperature, wind speed, atmospheric pressure and precipitation) and CO and ozone concentrations in year 2008 and 2010 were recorded by an automatic meteorological station (the Beijing Urban Ecosystem Research Station, RCEES) located at the same site. Besides, ozone concentrations in summers of 2008-2010 were also provided by the Chinese Research Academy of Environmental Science (CRAES) which lies in the north of Beijing city $\left(40^{\circ} 2^{\prime} \mathrm{N}, 116^{\circ} 24^{\prime} \mathrm{E}\right)$ between 5 th and 6th ring roads.

\subsection{Statistical analysis}

Statistical analysis was performed using SPSS software and Microsoft Excel. Statistically significant comparisons were identified using analysis of variance (ANOVA) and Least Significant Difference (LSD) calculations at an alpha level of $0.05(\alpha=0.05)$. Flux data were In-transformed, as needed, to normalize the distributions prior to statistical analysis.

\section{Results and discussion}

3.1. Average diurnal variations of atmospheric carbonyls and BTEX during the summer seasons

Eight carbonyls were identified in the ambient air of Beijing, namely formaldehyde, acetaldehyde, acetone, propionaldehyde, butyraldehyde, benzaldehyde, valeraldehyde and hexaldehyde. Among the carbonyls, formaldehyde, acetaldehyde, acetone were by far the most abundant carbonyls, and could be detected in every sample, as did for BTEX compounds. The average diurnal variations of the three most abundant carbonyls and BTEX during the three consecutive summer seasons from 2008 to 2010 are shown in Fig. 1. The BTEX compounds exhibited the same diurnal variation trends with minimal values appearing in the early afternoon. Besides their sources strength variation, their variation trends were mainly ascribed to the diurnal course of meteorological conditions, such as the inversion layer in the morning that favors for pollutants accumulation, and elevation of boundary layer at noon that results in fast diffusion. The three most abundant carbonyls also revealed same diurnal variation trends, but contrary to those of BTEX and the diurnal course of meteorological condition, their maximum appeared at noon, indicating that secondary photochemical formation was an important source for atmospheric carbonyls in Beijing.

\subsection{Yearly average variations of atmospheric carbonyls and BTEX during the summer seasons}

The yearly average variations of formaldehyde, acetaldehyde and acetone during the three investigating summer seasons are 

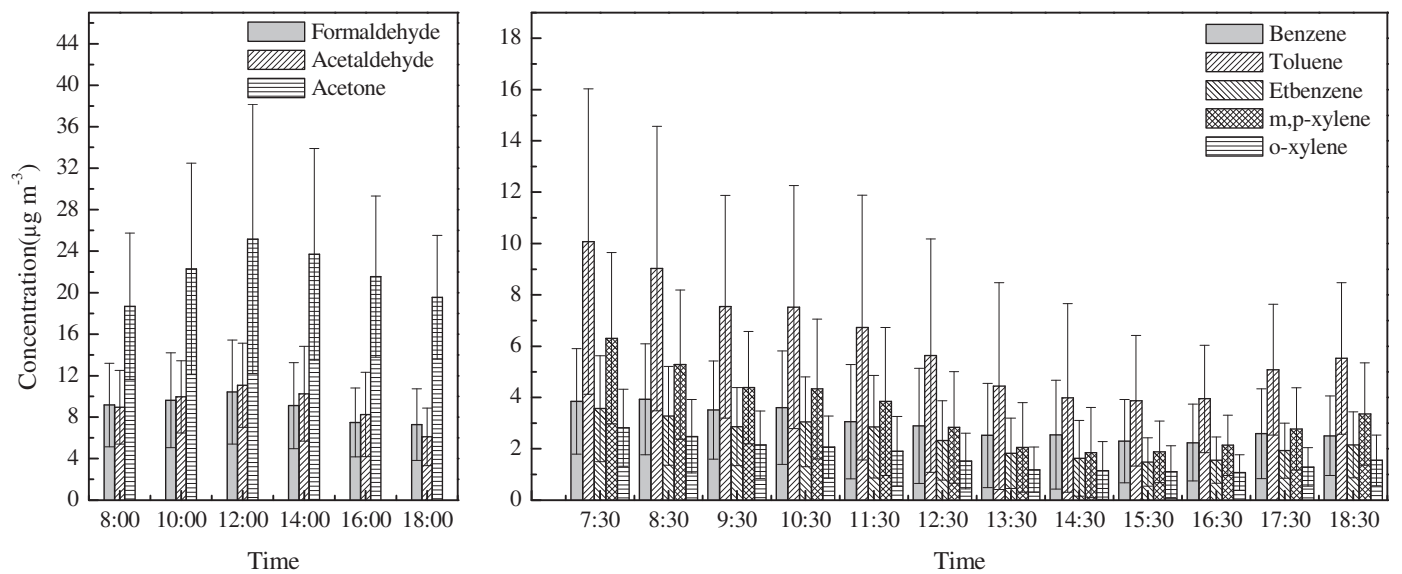

Fig. 1. Average diurnal variations of three principal carbonyls and BTEX during summer seasons (July-August) of 2008-2010 (Sampling days of 59 days).

listed in Table 1. The results of carbonyls in summers of 2005 $(n=110)$ and $2006(n=62)$ that measured at the same sampling site by our group (Pang and $\mathrm{Mu}, 2006$ ) are also presented for comparison. It is evident for the yearly increments of the total carbonyls from 2005 to 2006 and from 2008 to 2010. Besides the influence of primary sources, metrological conditions and photochemical reactions also play great role on atmospheric carbonyls. Because the sampling days in this study were selected no raining days and approximately same number of clear days for each summer, only the influence of wind speed was analyzed. The average wind speeds during the sampling days in 2008, 2009 and 2010 were $1.9 \mathrm{~m} \mathrm{~s}^{-1}, 1.9 \mathrm{~m} \mathrm{~s}^{-1}, 2.1 \mathrm{~m} \mathrm{~s}^{-1}$, respectively. It is evident that wind speed couldn't account for the yearly increment of atmospheric carbonyls. It should be mentioned that the yearly variation of acetone was not inconsistent with formaldehyde and acetaldehyde, e.g. the extremely high concentrations of acetone occurred in 2006 and 2010 among the five investigated years, indicating that the concentration of acetone might be strongly and irregularly affected by local direct or indirect emissions nearby the sampling site. Without considering acetone, the yearly increase rate of the total carbonyls from 2005 to 2006 and from 2008 to 2010 was about $10 \%$, which was coincident with the yearly increment of number of cars in Beijing since 2005 (Liu et al., 2009a). Compared with 2005 and 2006, the concentrations of carbonyls other than acetone in 2008 reduced about 50\%, which mainly owed to the strict control measures for the "green Olympic Games" in summer of 2008 (BOCOG, 2005; Hao and Wang, 2005). The continuous lower levels of atmospheric carbonyls in 2009 and 2010 than those in 2005 and 2006 were mainly ascribed to the implementation of

Table 1

Average concentrations of carbonyls and BTEX in summers $\left(\mu \mathrm{g} \mathrm{m}^{-3}\right)$.

\begin{tabular}{|c|c|c|c|c|c|}
\hline & 2005 & 2006 & 2008 & 2009 & 2010 \\
\hline$n$ & 110 & 62 & 126 & 109 & 88 \\
\hline Formaldehyde & $19.5 \pm 7.5$ & $21.7 \pm 14.2$ & $7.8 \pm 3.8$ & $8.8 \pm 4.7$ & $10.2 \pm 4.2$ \\
\hline Acetaldehyde & $14.1 \pm 6.6$ & $16.7 \pm 8.8$ & $7.9 \pm 3.6$ & $9.5 \pm 5.1$ & $9.7 \pm 3.9$ \\
\hline Acetone & $20.7 \pm 7.3$ & $31.2 \pm 22.3$ & $17.7 \pm 5.7$ & $18.4 \pm 8.1$ & $28.7 \pm 10.8$ \\
\hline Total & $54.3 \pm 20.0$ & $69.6 \pm 36.0$ & $33.4 \pm 12.9$ & $36.7 \pm 14.1$ & $48.6 \pm 15.2$ \\
\hline$n$ & & & 252 & 218 & 176 \\
\hline Benzene & & & $3.3 \pm 2.0$ & $3.2 \pm 2.3$ & $2.1 \pm 1.5$ \\
\hline Toluene & & & $5.6 \pm 4.0$ & $8.6 \pm 5.5$ & $5.9 \pm 3.7$ \\
\hline Ethylbenzene & & & $2.1 \pm 1.4$ & $3.3 \pm 2.1$ & $2.3 \pm 1.4$ \\
\hline m,p-xylene & & & $3.3 \pm 2.2$ & $4.6 \pm 3.4$ & $3.4 \pm 2.4$ \\
\hline o-xylene & & & $1.7 \pm 1.3$ & $1.9 \pm 1.3$ & $1.7 \pm 1.2$ \\
\hline Total & & & $16.0 \pm 9.3$ & $21.5 \pm 13.7$ & $15.4 \pm 9.3$ \\
\hline
\end{tabular}

more strict emission standard for cars, e.g. the vehicles with exhaust emissions failed to meet the European No.1 standard were all-day forbidden on the roads since 1 July, 2008.

In contrast to the atmospheric carbonyls, the total concentrations of atmospheric BTEX increased about 35\% from 2008 to 2009, and then decreased to the level of 2008 in 2010 (Table 1), which was inconsistent with the increasing emission of cars. The ratios $(0.36,0.38)$ of benzene to toluene $(B / T)$ were almost at same level in years 2009 and 2010, indicating that the proportion of each source for BTEX during the two years was relatively stable. Therefore, the different meteorological conditions during the sampling periods among the three investigating years were suspected for the abnormal yearly variations, e.g. the relatively larger average wind speed during the sampling days in 2010. It should be mentioned that the B/T values in 2009 and 2010 were much lower than that in $2008(0.66)$ and the average value of $0.60(\mathrm{wt} / \mathrm{wt})(\sigma=0.2)$ from the Chinese vehicle exhaust (Barletta et al., 2005; Liu et al., 2009a). Because the strict control measures were adopted for various sources of BTEX in 2008, vehicles emissions might become the dominant sources for atmospheric BTEX during such a special summer season. Whereas the extremely low B/T values in 2009 and 2010 indicated that the sources other than vehicle exhaust, such as evaporation of solvents and paints and so on might also make important contribution to atmospheric BTEX in Beijing city. Because the sources other than vehicle emissions are usually irregular emissions, their yearly emissions must vary significantly and might be also partially responsible for the irregular yearly variation of atmospheric BTEX.

\subsection{The contribution of local photochemical reactions to atmospheric carbonyls}

As mentioned above, BTEX are solely from the primary sources of human activities, while carbonyls are also from contribution of photochemical reactions besides theirs primary sources. If atmospheric BTEX and carbonyls were from the same primary sources, the ratios of carbonyls to BTEX would be useful indicators for illustrating photochemical contribution to atmospheric carbonyls, because the ratios could partly counteract the influence of diffusion (Grosjean, 1982; Satsumabayashi et al., 1995; Possanzini et al., 2002). To check the primary originations of atmospheric benzene, formaldehyde and acetaldehyde, the correlations between benzene and formaldehyde as well as acetaldehyde during winter seasons of 2008-2009 were analyzed by SPSS (13.0), and significant correlation between benzene and formaldehyde $(R=0.64, p=0.01$, 
$n=174)$ as well as acetaldehyde $(R=0.78, p=0.01, n=174)$ were found, suggesting that the three pollutants were probably from common primary sources in Beijing. As shown in Fig. 2, the distinct diurnal variations for the ratios of formaldehyde to benzene $(F / B)$ and acetaldehyde to benzene (A/B) further indicated that photochemical reactions made great contribution to atmospheric carbonyls in summer of Beijing, which was much more pronounced than the diurnal variations of atmospheric formaldehyde and acetaldehyde illustrated in Fig. 1.

The contribution percentage $(\mathrm{P})$ of photochemical reactions to the atmospheric carbonyls during the summer seasons was further quantified based on the similar method developed by Satsumabayashi et al. (1995) and Possanzini et al. (2002). In this study, the ratios of formaldehyde and acetaldehyde to benzene instead of CO (Satsumabayashi et al., 1995) or toluene (Possanzini et al., 2002) were adopted for estimation.

$\mathrm{P}=\frac{([\mathrm{RCHO}] /[\mathrm{B}])_{\mathrm{D}}-([\mathrm{RCHO}] /[\mathrm{B}])_{\mathrm{M}}}{([\mathrm{RCHO}] /[\mathrm{B}])_{\mathrm{D}}} \times 100 \%$

where $[\mathrm{RCHO}]$ and $[\mathrm{B}]$ denote the two hourly average concentration of aldehydes and benzene; $\mathrm{D}$ represents daytime and $\mathrm{M}$ represents the minimum value (7:00-9:00 in the morning) of the day. The diurnal variations of the contribution percentages of photochemical reactions to both formaldehyde and acetaldehyde were similar to Fig. 2, and only the maximal contribution percentages appeared around noon or early afternoon (12:00-14:00) were listed in Table 2, together with the results of Satsumabayashi et al. (1995) and Possanzini et al. (2002). It could be seen that the maximal contributions of photochemical reactions to atmospheric carbonyls during summer time in Beijing were almost at the same level as the reported values of other cities that near the same latitude (Urawa and Takasaki). Because of the fast photolysis rate and rapid reactions of aldehydes with $\mathrm{OH}$ radicals during daytime especially during noon, the above estimations which were much lower than our previous estimation ( $\sim 78 \%$ for formaldehyde) based on the concentration difference between summer and winter (Pang and $\mathrm{Mu}, 2006)$, could only represented the lowest limits.

\subsection{Ozone formation potential}

VOC-sensitive chemistry has been found to be most likely to occur in central locals in large cities (reviewed by Sillman, 1999), therefore, it is very important to distinguish the contribution of
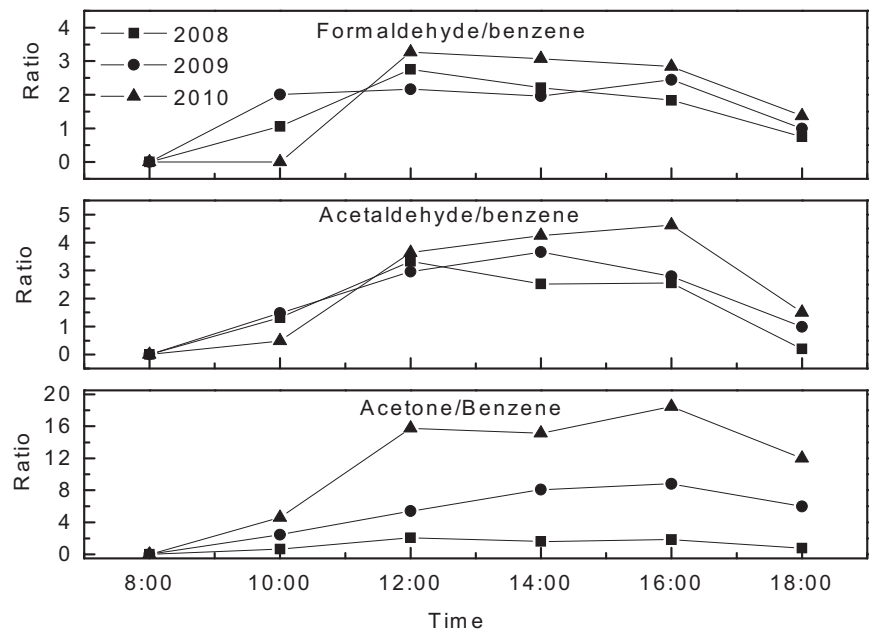

Fig. 2. Average diurnal variations of the ratios of three principal carbonyls to benzene in different years.
Table 2

Comparison of the maximum contribution of photochemical formation to atmospheric carbonyls between Beijing and those of other cities (\%).

\begin{tabular}{lllll}
\hline Year & Formaldehyde & Acetaldehyde & City & Ref. \\
\hline 2008 & 56.9 & 60.3 & Beijing & This work \\
2009 & 48.3 & 58.3 & Beijing & This work \\
2010 & 47.6 & 53.6 & Beijing & This work \\
1984 & 53.0 & 70.0 & Urawa & Satsumabayashi et al. (1995) \\
1984 & 50.0 & 65.0 & Takasaki & Satsumabayashi et al. (1995) \\
1996 & 80.0 & 90.0 & Rome & Possanzini et al. (2002) \\
\hline
\end{tabular}

individual VOC to ambient ozone for efficient control measure in the urban areas. The ozone formation potential (OFP), which is the product of the concentration of individual VOC and the maximum incremental reactivity (MIR) developed by Carter (1994), is a widely used method for evaluating the maximum ozone formation capacity in cities where ozone formation are VOC-sensitive. The OFPs of carbonyls, BTEX and CO in Fig. 3 were calculated based on the average concentration of the three summers. The sum of the OFP of formaldehyde and acetaldehyde estimated in this study was $114.1 \mu \mathrm{g} \mathrm{m}^{-3}$, accounting for $69 \%$ of the contribution of total carbonyls $\left(166.1 \mu \mathrm{g} \mathrm{m}^{-3}\right.$ ) measured. The only available OFP of carbonyls ( $374.6 \mu \mathrm{g} \mathrm{m}^{-3}$ ) estimated by Duan et al. (2008) in 2006 summer of Beijing was two times more than ours. As did for the carbonyls, the OFP of BTEX estimated by Duan et al. $\left(143.7 \mu \mathrm{g} \mathrm{m}^{-3}\right)$ was also two times greater than our estimation $\left(65.4 \mu \mathrm{g} \mathrm{m}^{-3}\right)$. Whereas another available OFP $\left(84.2 \mu \mathrm{g} \mathrm{m}^{-3}\right)$ of BTEX estimated by Xie et al. (2008) for the data measured during August-September in 2006 was only $29 \%$ greater than ours. Although the data of Duan et al. (2008) might be less representative due to their estimation only based on four days measurements, the average concentration of carbonyls measured in our group in 2006 summer was roughly in agreement with theirs. Although the number of cars in Beijing sharply increased in recent years, the less OFP values of carbonyls and BTEX in comparison with the two estimations in 2006 further implied that the air clean actions adopted in Beijing in resent years were effective for reduction of them. The OFP of CO $\left(100.8 \mu \mathrm{g} \mathrm{m}^{-3}\right)$, which was neglected for estimation in previous studies, was the highest among the species investigated in this study.

\subsection{The photochemical reactivity in Beijing}

The ratio of ethylbenzene-m,p-xylene (E/X) in the urban area is usually used as an indicator for photochemical reactivity since they are usually from common sources but the reaction rate constant of

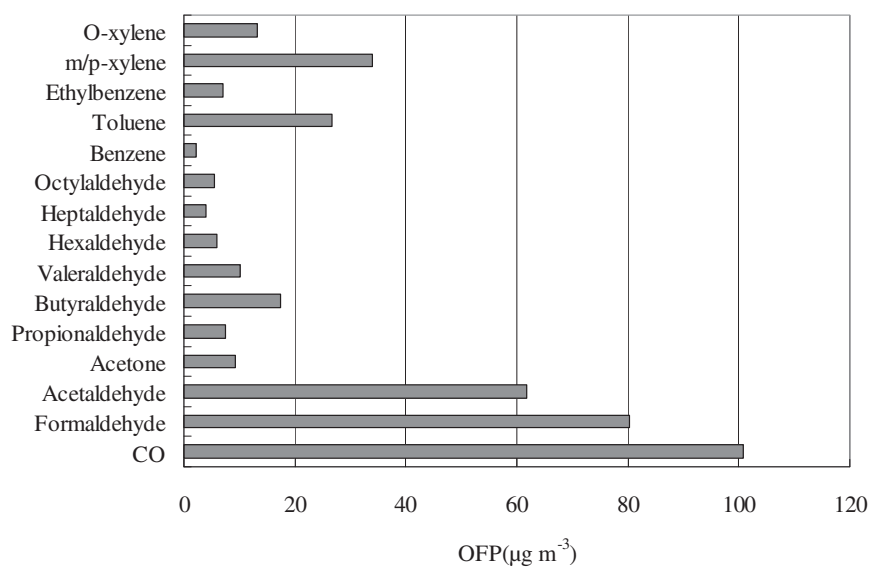

Fig. 3. Contribution of the individual species to the OFPs in Beijing. 

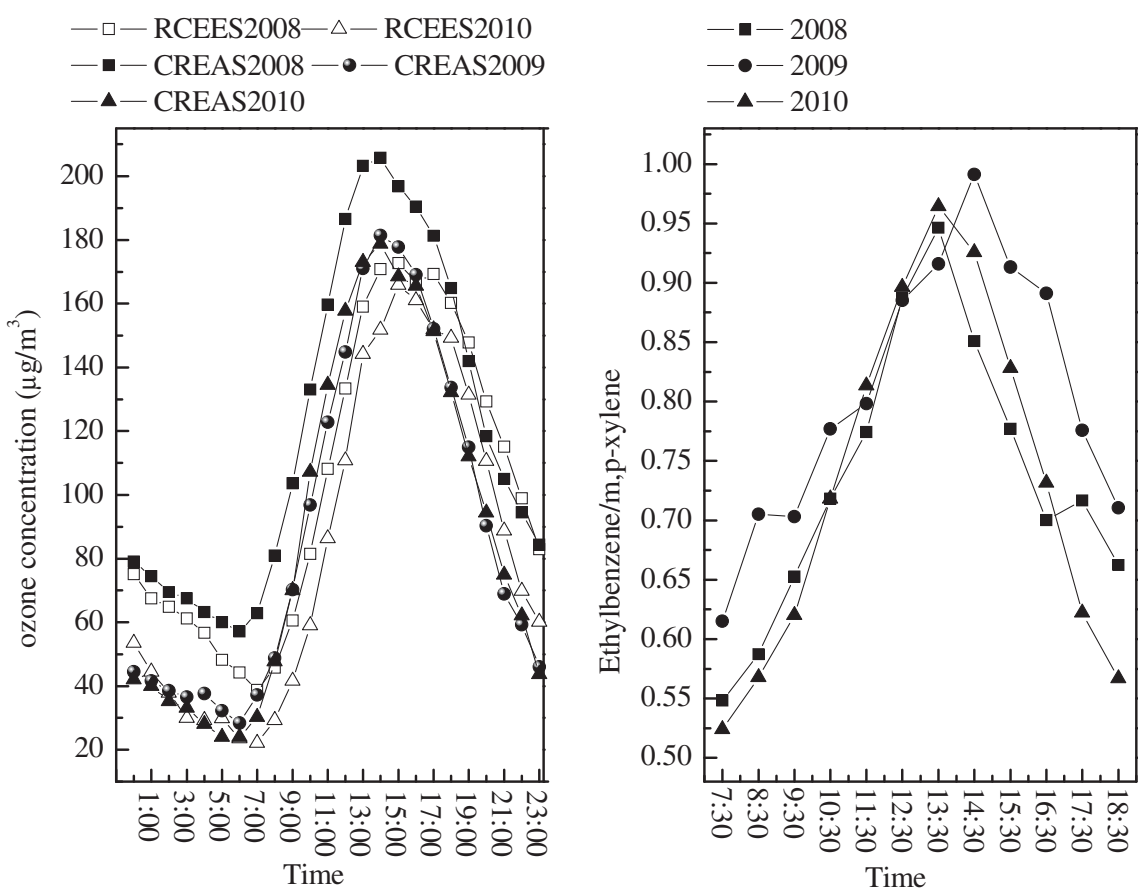

Fig. 4. Average diurnal variations of ozone concentration and the average ratios of ethylbenzene-m,p-xylene in different years.

m,p-xylene with $\mathrm{OH}$ radical is about a factor of 3 higher than that of ethylbenzene (Nelson and Quigley, 1983; Atkinson, 2007; Sotitris et al., 2011). The significant linear correlation $\left(R^{2}=0.92, n=862\right.$, $p=0.01$ ) between $\mathrm{m}, \mathrm{p}$-xylene and ethylbenzene during these three summer seasons further confirmed they were mainly from common sources in Beijing. The average diurnal variations of the ratios of ethylbenzene-m,p-xylene and the concentrations of $\mathrm{O}_{3}$ are presented together in Fig. 4 to illustrate the atmospheric photochemical reactivity in Beijing. Because the $\mathrm{O}_{3}$ analyzer in the station of RCEES (where BTEX and carbonyls were sampled) was breakdown during July-2009, only the data of 2008 and 2010 were illustrated. The similar diurnal variation trends of the $\mathrm{E} / \mathrm{X}$ ratio and $\mathrm{O}_{3}$ further confirmed that the $\mathrm{E} / \mathrm{X}$ ratio is a useful indicator for photochemical reactivity. It should be mentioned that the peak $\mathrm{O}_{3}$ concentrations in 2008 at both stations were the highest among the three years; while no significant difference of the peak $\mathrm{E} / \mathrm{X}$ ratios were observed. $\mathrm{O}_{3}$ peak concentration is not only determined by local photochemical reactivity, but also influenced by its local background level (Reddy et al., 2010). The evident reduction of $\mathrm{NO}_{x}$ (He et al., 2010; Wang et al., 2010; Xin et al., 2010) due to the strict control measures during the 2008 summer season (including July-August) greatly mitigated the $\mathrm{O}_{3}$ titration by NO during night time, and thus $\mathrm{O}_{3}$ kept extremely high concentration at early morning. Considering almost with same $\mathrm{O}_{3}$ formation rates at both stations during morning hours among the three years, the observed difference of $\mathrm{O}_{3}$ peaks was mainly ascribed to the difference of local background $\mathrm{O}_{3}$ levels in the early morning. This phenomenon also revealed that effective control measure for mitigating $\mathrm{O}_{3}$ pollution in the megacity of Beijing is a very difficult task and one of the major scientific challenges.

\section{Conclusion}

The average yearly concentrations of carbonyls evidently increased year by year, while for BTEX increased from 2008 to 2009 and then decreased in 2010. The distinct difference between the yearly variations of carbonyls and BTEX was mainly ascribed to the different sources for them. The main source for BTEX in summer of 2008 was ascribed to vehicle emission, and sources other than vehicle emission also made great contribution to atmospheric BTEX in 2009 and 2010 because of the extremely low $\mathrm{B} / \mathrm{T}$ ratios. Based on the yearly increasing rate of carbonyls, we suspect that vehicle emission might be the dominant sources for them which were mainly from photochemical reactions of VOCs. The OFPs of the carbonyls, BTEX and CO measured by this study indicated they played important roles in ozone formation in Beijing city, and should be paid attention for further effectively control measures.

\section{Acknowledgments}

This work was financially supported by the Chinese National Natural Science Foundation (40830101, 41075094, 21177140 and 20977097), the Special Fund for Environmental Research in the Public Interest (201009001), and National Basic Research and the Development Program 973 (2010CB732304). The authors would like to acknowledge CNRS and the French Embassy in Beijing for their support.

\section{References}

Aschmann, S.M., Arey, J., Atkinson, R., 2001. Atmospheric chemistry of three $C_{10}$ alkanes. Journal of Physical Chemistry A 105 (32), 7598-7606.

Atkinson, R., 2007. Gas-phase tropospheric chemistry of organic compounds: a review. Atmospheric Environment 41, 200-240.

Atkinson, R., Arey, J., 2003. Gas-phase tropospheric chemistry of biogenic volatile organic compounds: a review. Atmospheric Environment 37, 197-219.

Baez, A.P., Padilla, H., Cervantes, J., Pereyra, D., Torres, M.C., Garcia, R., Belmont, R. 2001. Preliminary study of the determination of ambient carbonyls in Xalapa City, Veracruz, Mexico. Atmospheric Environment 35, 1813-1819.

Barletta, B., Meinardi, S., Simpson, I.J., Zou, S., Rowland, F.S., 2008. Ambient mixing ratios of nonmethane hydrocarbons (NMHCs) in two major urban centers of the Pearl River Delta (PRD) region: Guangzhou and Dongguan. Atmospheric Environment 42, 4393-4408.

Barletta, B., Meinardi, S., Rowland, F.S., Chan, C., Wang, X., Zou, S., Chan, L., Blake, D.R., 2005. Volatile organic compounds in 43 Chinese cities. Atmospheric Environment 39, 5979-5990. 
Beijing Organizing Committee for the Games of the XXIX Olympic Games (BOCOG), 2005. Green Olympics in Beijing. http://en.beijing2008.cn/bocog/environment/ guidelines/n214068405.shtml.

Carlier, P., Hannachi, H., Mouvier, G., 1986. The chemistry of carbonyl compounds in the atmosphere- a review. Atmospheric Environment 20, 2079-2099.

Carter, W., 1994. Development of ozone reactivity scales for volatile organic compounds. Journal of the Air \& Waste Management Association 44, $881-889$.

Crump, K.S., 1994. Risk of benzene-induced leukemia: a sensitivity analysis of the pliofilm cohort with additional follow-up and new exposure estimates. Journal of Toxicology and Environmental Health 42, 219-242.

Duan, J., Tan, J., Yang, L., Wu, S., Hao, J., 2008. Concentration, sources and ozone formation potential of volatile organic compounds (VOCs) during ozone episode in Beijing. Atmospheric Research 88, 25-35.

Dutta, C., Som, D., Chatterjee, A., Mukherjee, A.K., Jana, T.K., Sen, S., 2009. Mixing ratios of carbonyls and BTEX in ambient air of Kolkata, India and their associated health risk. Environmental Monitoring and Assessment 148, 97-107.

EPA, 1999. Compendium of Methods for the Determination of Toxic Organic Compounds in Ambient Air, second ed.

Grosjean, D., 1982. Formaldehyde and other carbonyls in Los Angeles ambient air Environmental Science \& Technology 16, 254-262.

Grosjean, D., Grosjean, E., Moreira, L., 2002. Speciated ambient carbonyls in Rio de Janeiro, Brazil. Environmental Science and Technology 36, 1389-1395.

Hao, J.M., Wang, L.T., 2005. Improving urban air quality in China: Beijing case study. Journal of the Air \& Waste Management Association 55, 1298-1305.

He, S.Z., Chen, Z.M., Zhang, X., Zhao, Y., Huang, D.M., Zhao, J.N., Zhu, T., Hu, M. Zeng, L.M., 2010. Measurement of atmospheric hydrogen peroxide and organic peroxides in Beijing before and during the 2008 Olympic Games: chemical and physical factors influencing their concentrations. Journal of Geophysical Research-Atmospheres $115 . \quad$ http://dx.doi.org/10.1029/ 2009JD013544

Larry, G.A., John, A.L., Regina, B., Joyce, M., Richard, H.J., Pamela, W., 1996. Sources and sinks of formaldehyde and acetaldehyde: an analysis of denver's ambient concentration data. Atmospheric Environment 30, 2113-2123.

Liu, J., Mu, Y., Zhang, Y., Zhang, Z., Wang, X., Liu, Y., Sun, Z., 2009a. Atmospheric levels of BTEX compounds during the 2008 Olympic Games in the urban area of Beijing. Science of the Total Environment 408, 109-116.

Liu, Y., Shao, M., Kuster, W.C., Goldan, P.D., Li, X., Lu, S., Gouw, J.A., 2009b. Source identification of reactive hydrocarbons and oxygenated VOCs in the summertime in Beijing. Environmental Science \& Technology 43, 75-81.
Nelson, P.F., Quigley, S.M., 1983. The m, p-xylenes: ethylbenzene ratio, a technique for estimating hydrocarbon age in ambient atmospheres. Atmospheric Environment 17, 659-662.

Pang, X., Mu, Y., 2006. Seasonal and diurnal variations of carbonyl compounds in Beijing ambient air. Atmospheric Environment 40, 6313-6320.

Pang, X., Mu, Y., 2007. Characteristics of carbonyl compounds in public vehicles of Beijing city: concentrations, sources, and personal exposures. Atmospheric Environment 40, 6313-6320.

Possanzini, M., Palo, V.D., Cecinato, A., 2002. Sources and photodecomposition of formaldehyde and acetaldehyde in Rome ambient air. Atmospheric Environment 39, 3195-3201.

Reddy, B.S.K., Kumar, K.R., Balakrishnaiah, G., Gopal, R.K., Reddy, R.R., Ahammed, Y.N., Narasimhulu, K., Reddy, L.S.S., Lal, S., 2010. Observational studies on the variations in surface ozone concentration at Anantapur in southern India. Atmospheric Research 98 (1), 125-139.

Satsumabayashi, H. Kurita, H. Chang, Y.S., Carmichael, G.R., Ueda, H. 1995 Photochemical formations of lower aldehydes and lower fatty acids under longrange transport in central Japan. Atmospheric Environment 29, 255-266.

Sillman, S., 1999. The relation between ozone, $\mathrm{NO}_{\mathrm{x}}$, hydrocarbons in urban and polluted rural environments. Atmospheric Environment 33, 1821-1845.

Song, Y., Shao, M., Liu, Y., Lu, S., Kuster, W., Goldan, P., Xie, S., 2007. Source apportionment of ambient volatile organic compounds in Beijing. Environmental Science \& Technology 41, 4348-4353.

Sotitris, V., Efisio, S., Julio, L., 2011. Intra-urban and street scale variability of BTEX, $\mathrm{NO}_{2}$ and $\mathrm{O}_{3}$ in Birmingham, UK: implications for exposure assessment. Atmospheric Environment 45, 5069-5078.

Wang, T., Nie, W., Gao, J., Xue, L.K., Gao, X.M., Wang, X.F., Qiu, J., Poon, C.N., Meinardi, S., Blake, D., Wang, S.L., Ding, a. J., Chai, F.H., Zhang, Q.Z., Wang, W.X., 2010. Air quality during the 2008 Beijing Olympics: secondary pollutants and regional impact. Atmospheric Chemistry and Physics 10 (16), 7603-7615.

Xie, X., Shao, M., Liu, Y., Lu, Sihua, Chang, C., Chen, Z., 2008. Estimate of initial isoprene contribution to ozone formation potential in Beijing, China. Atmospheric Environment 42, 6000-6010.

Xin, J.Y., Wang, Y.S., Tang, G.Q., Wang, L.L., Sun, Y., Wang, Y.H., Hu, Bo., Song, T., Ji, D.S., Wang, W.F., Li, L., Liu, G.R., 2010. Variability and reduction of atmospheric pollutants in Beijing and its surrounding area during the Beijing 2008 Olympic Games. Chinese Science Bulletin 55 (18), 1937-1944.

Xu, Z., Liu, J., Zhang, Y., Liang, P., Mu, Y., 2010. Ambient levels of atmospheric carbonyls in Beijing during the 2008 Olympic Games. Journal of Environmental Sciences 22 (9), 1348-1356. 